\title{
A LUTA DOS MOVIMENTOS SOCIAIS PELA EFETIVAÇÃO DE DIREITOS E O COMPROMISSO ÉTICO-POLÍTICO-JURÍDICO DA REDE NACIONAL DE ADVOGADOS E ADVOGADAS POPULARES.
}

\author{
Tony Rocha \\ Programa de Pós-graduação em Serviço Social - Aluno Especial do Mestrado \\ Disciplina: O Mundo Rural: a questão agrária e as relações capital/trabalho no campo \\ Universidade Estadual Paulista "Júlio de Mesquita Filho" - UNESP/Campus Franca \\ e-mail: tony.pedro@terra.com.br
}

RESUMO: Vivemos em uma sociedade pautada pelo neoliberalismo, que é a forma atual do modo de produção capitalista, responsável pela imensa desigualdade social, criando legiões de excluídos, traduzidas em desempregados, sem teto, sem terra, sem dignidade humana. Este quadro de exploração é preservado com o apoio do aparato judicial, que utiliza o poder configurador do Estado para manutenção das desigualdades sociais. Através do direito, exerce um controle social militarizado e verticalizado, que cotidianamente se estende muito além da repressão, para ser configurador da vida social. Diante de toda essa lógica estrutural de perpetuação da dominação, reproduzida nas faculdades de direito, na imprensa, nos órgãos do Estado e na sociedade em geral, fica difícil perceber que um outro direito é possível, embora alguns o visualizem como necessário. Mas o Direito pode e deve estar ligado à superação das explorações e desigualdades sociais, buscando numa teoria jurídico-crítica um "Direito Alternativo" ou um "uso alternativo do Direito". A união da advocacia popular com os movimentos sociais dar-se-á partir da concepção de movimento enquanto agente transformador da sociedade, com isto o jurista se torna um militante da causa defendida, em virtude do comprometimento político-ideológico com as classes oprimidas. Diante deste contexto surge a Rede Nacional de Advogados e Advogadas Populares (Renap), como um organismo articulador da advocacia popular e um apoio efetivo aos que ousam enfrentar, no pântano nebuloso do judiciário, o direito usado para negar o Direito dos excluídos.

PALAVRAS-CHAVE: Movimentos Sociais. Advocacia Popular. RENAP. Estado. Direito. 


\section{APRESENTAÇÃO}

O crescente desenvolvimento do capitalismo que hoje nos apresenta na forma neoliberal, constrói a sociedade na perspectiva da exclusão social, elevando as desigualdades e a concentração de terras e de rendas.

Com o Estado vinculado ao capital financeiro transnacional e atuando na manutenção do sistema, a imensa maioria da população tem seus direitos sociais desrespeitados, muitas vezes sob a alegação de que é preciso flexibilizar estes direito para se poder crescer.

Através dos grandes veículos de comunicação, da educação e do direito formal, é transmitida uma visão de que não existe a possibilidade de mudança, pois o processo para que se consiga resolver todos os problemas sociais deverá ser necessariamente lento e gradual.

Diante de toda a exploração vivida, alguns setores da população criam um sentido de luta de classe, se organizando em movimentos socais para enfrentar o poder constituído.

Visualizando esta efervescência, o direito passou a ser usado, por estes movimentos sociais, como "um agente revolucionário", o que apresentou novas perspectivas para atuação profissional dentro do Direito, que estejam baseadas no compromisso ético e político com os excluídos, visando a construção de um novo direito, que não esteja a serviço da dominação social.

O jurista deve estar comprometido de forma histórica e crítica com a realidade social, como o fazem os movimentos sociais, tornando-se um militante das causas que advoga, trabalhando juridicamente para contribuir na efetivação das lutas desses movimentos.

Dentro dessa perspectiva, apresentar a Rede Nacional de Advogados e Advogadas Populares (Renap), como um organismo articulador da advocacia popular e um apoio efetivo aos que ousam enfrentar, no pântano nebuloso do judiciário, o direito usado para negar o Direito dos excluídos. 


\section{INTRODUÇÃO}

Vivemos em uma sociedade pautada pelo neoliberalismo, que é a forma atual do modo de produção capitalista, responsável pela imensa desigualdade social, criando nos paises periféricos legiões de excluídos, traduzidas em desempregados, sem teto, sem terra, sem dignidade humana.

Toda América Latina sucumbe diante desta devastadora realidade de exploração, dominação e exclusão, em que a principal causa é o processo de globalização neoliberal, onde os governos, alinhados ao modelo, adotam um conjunto de medidas políticas que compreendem na liberalização do comércio, nas privatizações, na redução ou eliminação da presença do Estado nas áreas de saúde, educação, assistência social, na política de flexibilização dos direitos e garantias trabalhistas e redução de salários.

Estas medidas visam salvaguardar o capital financeiro internacional, que adentra nos países latino americanos com a intenção de explorar sua população e seus recursos naturais, como nos ensina o eminente economista Celso Furtado:

As novas formas que está assumindo o capitalismo nos países periféricos não são independentes da evolução global do sistema. Contudo, parece inegável que a periferia terá crescente importância nessa evolução, não só porque os países cêntricos serão cada vez mais dependentes de recursos naturais não produtíveis por ela fornecidos, mas também porque as grandes empresas encontrarão na exploração de sua mão-de-obra barata, um dos principais pontos de apoio para firmar-se no conjunto do sistema. (Furtado, 1974. P. 60)

Os governos não foram capazes de responder às necessidades sociais da imensa maioria da população latina americana, por não se contraporem às pressões dos interesses financeiros internacionais, com isso deixaram de fazer as reformas necessárias para o bem estar social, o que elevou a índices alarmantes a concentração de renda e as desigualdades sociais.

Com os governos submissos ao chamado "consenso de Washington" e sem a perspectiva de que eles realizassem as reformas ou mudanças estruturais que diminuísse ou eliminasse as desigualdades sociais, surgem como novos sujeitos os Movimentos Sociais.

Estes Movimentos Sociais em luta contra a exploração do capital estabeleceram uma resistência contra a devastação causada pelo neoliberalismo, 
captando com senso de fluidez e flexibilidade a formulação de uma nova identidade cultural, independente de qualquer discurso institucional.

Sua existência está intimamente ligada a temas relacionados ao desenvolvimento da democracia, da cidadania, da cultura, do meio ambiente, da emancipação, e por sua práxis e crítica tem despertado interesse da sociedade civil para as relações entre Estado e sociedade, o que ocasiona uma busca por forma alternativas para o enfrentar os projetos normatizadores da ordem e do poder global.

\section{O EFEITO DO NEOLIBERALISMO NO BRASIL}

No Brasil, incluído dentro desse processo globalizado, há um grande número de trabalhadores urbanos que está desempregado e que é agredido pela fome, pela falta de moradia digna e de vagas nas escolas, pelo sistema de saúde que está em permanente crise e pela agonizante seguridade social, vítima das quadrilhas que desviam o erário público e da falta de funcionários, fazendo com que não sejam atendidos os que dela necessitam.

No campo a realidade é ainda mais cruel, pois, além dos salários serem muito mais baixos que os dos trabalhadores urbanos, há um número muito maior de trabalhadores rurais permanentemente desempregados ou subempregados.

Neste setor também se destacam o trabalho análogo ao de escravo e o trabalho infantil, existindo, ainda, os trabalhadores sazonais.

Estes trabalhadores sazonais laboram na época de safra, via de regra, migrando para áreas onde as empresas do agronegócio os exploram cada vez mais, frustrando ou "flexibilizando" os direitos trabalhistas, resguardados por um numeroso exército de reserva e pela escassez do trabalho rural.

As condições de trabalho e as relações de dominação e exploração impostas em especial aos assalariados rurais são uma afronta à dignidade humana. Pode-se constatar inclusive casos que beiram a escravidão no campo. Os direitos trabalhistas e sociais estabelecidos na constituição são completamente desrespeitados e desconhecidos dos próprios trabalhadores. Como indicador deste fato, basta dizer que 65\% dos assalariados rurais sequer possuem carteira de trabalho assinada, ou que apenas $40 \%$ dos trabalhadores possuem trabalho $O$ ano todo. Os demais vivem num contínuo processo de trabalho temporário e desemprego. (MAURO \& PERICÁS, 2001, p. 71). 
Somente na última década do século XX o setor agrícola perdeu mais de um milhão de postos de trabalho, perda esta causada pela mecanização do campo brasileiro ou pela especulação imobiliária das terras agricultáveis deixadas como reserva de valor.

Se não bastasse a oligarquia agrária, que explora uma grande camada dos trabalhadores rurais, agora também está no campo a burguesia financeira, que descobriu na terra um mercado seguro para seus capitais excedentes.

Outro dado do campo brasileiro é o vertiginoso aumento do número de trabalhadores rurais sem terra, expulsos da terra pela violência da grilagem e pelo vergonhoso índice de concentração de terra produzida pelo capitalismo, que é um dos maiores de todo o mundo.

A burguesia financeira adquire grandes quantidades de terra, o latifúndio, que na maioria das vezes é subtilizada com a pecuária extensiva, como modo de maquiar a produtividade da terra, já as oligarquias agrárias utilizam da monocultura agrícola para a exportação, principalmente da cana de açúcar e soja transgênica, e da exploração do trabalhador rural.

Em ambos os casos, o latifúndio está aliado ao capital internacional e juntos utilizam o aparato repressor do Estado na manutenção das desigualdades, através da criminização dos movimentos que lutam pela transformação social.

Por fim, como ponto de apoio à manutenção de todas as mazelas dos oprimidos setores populares, está o poder da imprensa, braço do grande negócio que são as telecomunicações, que com sua parcialidade e alinhamento aos estratos dominantes do capitalismo transnacional, desdobra-se na tentativa de criminalizar e deslegitimar todas as tentativas de mudanças sociais.

\section{OS MOVIMENTOS SOCIAIS}

O fenômeno de surgimento de frentes populares ou movimentos de base, hoje denominado de movimentos sociais, se deu a partir de um processo de alienação das organizações políticas tradicionais, o que gerou uma perda de confiança por parte dos excluídos.

Um outro fator que causou este surgimento foi o fato da população excluída não querer adiar o sonho de uma sociedade justa e igualitária, tratando de realizá-la na prática da luta cotidiana pela sobrevivência. 
Historicamente, o termo movimentos sociais foi introduzido na sociologia por Lorenz Von Stein em 1840. Com o passar dos anos, o tema ganhou importância e fez com que, desde seu surgimento até os dias de hoje, muitos pensadores se debruçassem no estudo dos movimentos sociais, para criar várias conceituações.

Uma das conceituações é a defendida por Ilse Scherer-Warren, na qual movimento social seria:

(...) uma ação grupal para transformação (a práxis) voltada para a realização dos mesmos objetivos (o projeto), sob a orientação mais ou menos consciente de princípios valorativos comuns (a ideologia) e sob uma organização diretiva mais ou menos definida (a organização e sua direção). (SCHERER-WARREN, 1987, p. 20)

À medida que se ampliam as tensões, os conflitos, as dominações políticas, econômicas, culturais, ideológicas, dá-se início a um processo de construção de uma nova identidade dos sujeitos sociais, que atuará como ponto de partida para o despertar da consciência de classe.

Esta nova identidade será construída a partir de um fator estrutural, no qual se percebe que as condições materiais do capitalismo e suas formas de opressão, e de um fator cultural, expressada numa cultura crítica em face dos autoritarismo e opressões, que se define na livre organização, na auto gestão, na democracia de base, no direito à diversidade, no respeito à individualização, na liberdade coletiva.

Nesse sentido, somente será considerado movimento social, segundo Scherer-Warren, o grupo organizado que atender a estas características, o que o levará a lutar pela efetivação de uma proposta de transformação social ou alteração dos padrões até então vigentes.

Os movimentos sociais não surgem ao acaso, são fruto da insatisfação dos setores socialmente subordinados com a realidade, causada pela opressão dos detentores de poder e pela inoperância do Estado, que não é garantidor dos direitos sociais e da dignidade humana.

Dentre todos os movimentos sociais da atualidade, o que mais se destaca, seja pelo número de pessoas envolvidas, seja pela gravidade da questão, é, sem dúvida, o movimento social agrário. 


\section{O DIREITO COMO INSTRUMENTO DO APARATO REPRESSOR DO ESTADO}

Este quadro de exploração é preservado com o apoio do aparato judicial, que utiliza o poder configurador do Estado para manutenção das desigualdades sociais. Através do direito exerce-se um controle social militarizado e verticalizado, que cotidianamente se estende muito além da repressão, para ser configurador da vida social.

O discurso jurídico tradicional é elaborado sobre um texto legal, mediante dogmas criados pelos legisladores, que em sua grande maioriam representam ou são financiados pelas burguesias e oligarquias, para o controle social da maioria da população.

Partindo desta legalidade formal, que suprime a legitimidade, pois produz as normas a partir de processos previamente fixados, viciados e estranhos à realidade social, o Estado cria um sistema perverso de controle social.

As teorias que se esgotam na legalidade formal permanecem, no entanto, como que suspensas no vazio, ao requerem um ponto de apoio legitimador do próprio processo de produção normativa, apoio que se tem procurado, quer na idéia de "soberano", quer na pressuposta e inquestionável legitimidade da "norma fundamental" ou ainda na regra última de reconhecimento. (ZAFARONI, 2001, p. 20)

O poder configurador do Estado, através de seu órgão legislador, mantém na legalidade somente as matérias que quer deixar dentro de seu âmbito, o que é uma reduzida parte da realidade, delimitando, assim, a atuação dos órgãos repressivos na manutenção do poder constituído.

Ao delimitar a atuação dos órgãos repressivos como fonte de preservação do poder das oligarquias e burguesias, o Estado consegue interiorizar nas massas dominadas uma disciplina militarizada, que uniformiza a obrigação de acatamento de uma autoridade superior, o Estado, dando a sensação que toda atividade é uma concessão da autoridade.

O Estado, a partir de seu poder configurador, torna a disciplina parte de um aparelho psicológico, que elimina a espontaneidade das reivindicações sociais dos excluídos, tornando-os submetidos a uma vigilância interiorizada da autoridade.

A partir da legalidade formal, o Estado cumpre uma função de disciplinarismo verticalizante, exercido de forma arbitrariamente seletiva, porque a lei 
a planifica desta forma, e o órgão legislativo a utiliza como uma forma de controle social.

Diante desta absurda constatação, fica demonstrado que o aparato repressor do Estado está estruturalmente montado para que a legalidade exerça, de forma arbitrária e seletiva, o controle social dos setores mais vulneráveis da sociedade.

É claro que poderia ser lembrado que o Estado é signatário de importantes Convenções e Tratados, assumindo com a comunidade internacional a luta pela igualdade social e pelos direitos humanos. Ou, ainda, que as Constituições, como Lei Maior do Estado, trazem garantias e proteção à pessoa humana, que não podem ser modificadas, a não ser por uma outra constituição.

Porém, estas normas garantidoras assumidas pelo Estado, não produzem nada mais do que expectativas nas camadas populares, pois quando são reivindicadas nas barras dos tribunais são frustradas pelo judiciário. Na medida que este poder traz para si os problemas que deveriam ser resolvidos por outras esferas de poder, deveria faze-lo em consonância com as disposições constitucionais, mas o que se observa é uma gritante aderência ao direito infraconstitucional.

Utilizando-se do mito da neutralidade, o Poder Judiciário tem ajudado na manutenção das opressões e explorações das classes mais baixas, vez que, através de seu comprometimento político-ideológico com as oligarquias e as burguesias dominantes, utiliza o direito para perpetuar essas desigualdades, explorações e dominações.

\section{A ADVOCACIA POPULAR COMO INSTRUMENTO DE LUTA}

Diante de toda essa lógica estrutural de perpetuação da dominação, reproduzida nas faculdades de direito, na imprensa, nos órgãos do Estado e na sociedade em geral, fica difícil perceber que um outro direito é possível, embora alguns o visualizem como necessário.

É mais fácil ao jurista e ao estudante sucumbirem à função conservadora das estruturas sociais e a postura normativo-positivista do direito, que reduz o papel do direito a um simples mantenedor da ordem.

Estes juristas corroboram consciente ou inconscientemente para esta manutenção, uns por falta de conhecimento de outras formas de interpretação do 
direito, pois nos processos de formação somente conheceram o direito positivista; outros por medo de enfrentar os juízes nos tribunais; outros por pura incompetência jurídica; e outros, ainda, por um comprometimento político-ideológico com as classes dominantes, como esclarece o eminente sociólogo Boaventura de Souza Santos:

(...) o conservadorismo dos magistrados, incubado em Faculdades de Direito anquilosadas, dominadas por concepções retrógradas da relação entre o direito e sociedade; 0 desempenho rotinizado assente na justiça retributiva, politicamente hostil à justiça distributiva e tecnicamente despreparada para ela; uma cultura jurídica 'cínica' que não leva a sério a garantia dos direitos, caldeada em largos períodos de convivência ou cumplicidade com maciças violações dos direitos constitucionais consagrados, inclinada a ver neles simples declarações programáticas, mais ou menos utópica; uma organização judiciária deficiente, com carências enormes tanto em recursos técnicos e materiais; um poder judicial tutelado por um poder executivo, hostil a garantia dos direitos ou sem meios orçamentais para a levar a cabo; (SANTOS, 1996, p. 22)

Mas o Direito pode e deve estar ligado à superação das explorações e desigualdades sociais, buscando na teoria jurídico-crítica um "Direito Alternativo" ou um "uso alternativo do Direito".

Para tanto, será necessário que os juristas procurem uma concepção renovadora, que utilize o Direito como forma de transformação social, fundamentada cientificamente na prática de um Direito que atue na construção de um mundo sem opressão.

$\mathrm{Na}$ conflituosa dualidade do dever de aplicar a lei e o dever de servir à Justiça, existe uma hierarquia de valores, na qual o maior valor é a justiça, que aplicada ao direito, deve ser utilizada para garantir, aos oprimidos, novos instrumentos de luta para a transformação social. A prática jurídica popular propõe um embasamento teórico que leva o direito a questionar a estrutura social e desempenhar um papel de referencial ético.

Nas últimas décadas do século XX, houve uma crescente coletivização dos conflitos sociais, como as greves, ocupações de terra, manifestações coletivas por moradia, desobediência à lei, movimento de resistência à devastação do meio ambiente, a organização das nações indígenas pela demarcação de suas áreas. Esta coletivização foi fruto da contradição da sociedade capitalista, pois o aumento da exploração alarga a faixa de marginalizados e excluídos e a concentração de riquezas. 
O processo de espoliação, urbanização, industrialização e consumismo, aliado ao distanciamento entre a ordem legal e a demanda dos direitos dos excluídos, faz com que a consciência política e a capacidade de organização das camadas subalternas cresça e cria-se, assim, uma condição conjuntural favorável à coletivização destes conflitos e ao surgimento de novos movimentos sociais.

A intensificação do conflito e a possibilidade de utilização do direito como instrumento de luta pelos movimentos sociais, levou a advocacia popular a se preparar para esta nova realidade social, onde os juristas estejam voltados para os marginalizados, contrapondo o projeto conservador.

Atualmente, os movimentos sociais vêm se apropriando do direito e dos instrumentais jurídicos como estratégias de luta, para desmistificar-se, assim, o direito como um conhecimento do qual só as classes dominantes são portadoras.

Neste caso o Direito pode ser comparado a "um agente revolucionário" (HERKENHOFF, 2001, p. ) a serviço do homem, que abre caminho para união dos juristas populares com os movimentos sociais.

Como os movimentos sociais fazem da luta pela Justiça uma luta antijudiciária, o que facilita a denúncia de arbitrariedades, impunidades e omissões do Estado, e os jurista fazem da luta pela Justiça uma luta judiciária, facilitada pela atuação dos movimentos sociais, existe a complementação da luta militante de ambos pela Justiça.

\section{ADVOCACIA POPULAR E OS MOVIMENTOS SOCIAIS}

A união da advocacia popular com os movimentos sociais dar-se-á a partir desta concepção de movimento, e, assim, o jurista torna-se um militante da causa defendida, em virtude do comprometimento político-ideológico com as classes oprimidas.

Estes juristas, como sujeito social, sentiram a necessidade de se organizar para defender esta concepção de direito e utilizá-lo como instrumento de transformação social e, com isso, resgatar a utopia da advocacia, que deve estar voltada para a defesa dos interesses das classes trabalhadoras e suas organizações.

A partir desta necessidade, surge em 1996, a Rede Nacional de Advogados e Advogadas Populares (Renap), que inicialmente se propunha a ser uma 
articulação autônoma, descentralizada, horizontal, de nível nacional, de advogados e advogadas, com o objetivo de prestar assessoria jurídica aos movimentos sociais.

A criação da Renap quebrou o isolamento dos advogados, que exerciam sua profissão de forma isolada, restrita a questões locais, apartada de uma visão ampla e geral do Direito e seus desafios.

Com a Renap, os advogados tiveram a compreensão política do papel desempenhado pelos movimentos sociais e passaram a utilizar este elemento político essas suas ações.

Mas o que seria uma articulação de advogados e advogadas, ampliou-se de forma a se tornar uma articulação de todos os operadores do Direito, quer sejam magistrados, promotores, procuradores, professores, acadêmicos, tendo como único requisito, identificar e assumir os compromissos e princípios da Rede:

- Amar e preservar a terra e os seres da natureza;

- Aperfeiçoar sempre nossos conhecimentos sobre a ciência jurídica com vistas à construção de um Direito que respeite o ser humano;

- Praticar a solidariedade e revoltar-se contra qualquer injustiça, agressão e exploração contra a pessoa, a comunidade e a natureza;

- Lutar contra o latifúndio, contra a submissão dos seres humanos ao capital, lutar contra o espírito individualista, competitivo, excludente e dominador;

- Transformar o direito em um importante instrumento dos movimentos sociais, na busca de novas e transformadoras fórmulas de acesso à justiça;

- Praticar a solidariedade, tendo sempre como guia superior a vontade de transformar a sociedade, abstendo-se de motivações de ordem meramente financeiras;

- Estar sempre atento aos acontecimentos da sociedade, buscando compreende-la cada vez mais profundamente, para inserir-se nessa realidade de maneira consciente e engajada com o compromisso de construir uma humanidade onde esteja assegurado a todos o direito de ser feliz, já que todos os homens nascem livre e iguais em dignidade.

(Cadernos da Renap, 2001, contra capa) 
Estes compromissos tornam o advogado popular um militante da causa que irá patrocinar nos tribunais e órgãos administrativos e contribuirá na efetivação dos Direitos reclamados pela luta dos movimentos sociais.

\section{CONSIDERAÇÕES FINAIS}

A luta cotidiana dos movimentos sociais é a única forma pacífica de revolução social e efetivação dos direitos fundamentais e sociais, que estão previstos na Constituição da República e nos inúmeros tratados internacionais de que o Estado é signatário.

Estes direitos e garantias proliferaram a partir dos países periféricos, que são onde estão mais marcantes as explorações e os constantes desrespeitos destas garantias.

Porém, apesar de existir um grande aparato normativo, o Poder Judiciário não está preparado para recepcioná-lo, pois, ainda está baseado no direito liberal burguês, que além de só reconhecer as relações inter pessoais, está nitidamente ligada a manutenção das explorações e do status quo..

Como o Estado não esta preparado para efetivar os direitos das massas exploradas, nega a estes estratos sociais o acesso a justiça.

Para tentar garantir o uso democrático do Direito, que para o Estado é uma exceção a regra, e colaborar para transformação social, os advogados populares lutam juntamente com os movimentos sociais.

Dessa união militante entre movimentos sociais e advocacia popular, através de ações jurídico-políticas e político-jurídicas, que se constroem novas bases para a constituição de uma sociedade não-capitalista. 


\section{REFERÊNCIAS BIBLIOGRÁFICAS}

CADERNOS DA RENAP. Série A Proteção Jurídica dos Povos da Terra. Alhandra. São Paulo: Rede Nacional dos Advogados e Advogados Populares, Ano 1, Número 1, 2001.

FURTADO, Celso. O mito do desenvolvimento econômico. Rio de Janeiro: Editora Terra e Paz, 1974.

HERKENHOFF, João Baptista. Para onde vai o Direito? Reflexões sobre o Papel do Direito e do Jurista. Porto Alegre: Livraria do Advogado Editora, 2001.

MAURO, Gilmar Geraldo. PERICÁS, Luiz Bernardo. Capitalismo e a Luta Política no Brasil na Virada do Milênio. São Paulo: Editora Xamã, 2001.

SANTOS, Boaventura de Souza. Os Tribunais nas Sociedades Contemporâneas. Porto: Editora Afrontamento, 1996.

SCHERER-WARREN, Ilse. Movimentos Sociais. Florianópolis: Editora UFSC, 1987.

SCHERER-WARREN, IIse. KRISCHKE, Paulo J. Uma Revolução no Cotidiano? Os Novos Movimentos Sociais na América do Sul. São Paulo: Editora Brasiliense, 1987.

STROZAKE, Juvelino José - organizador. A Questão Agrária e a Justiça. São Paulo: Editora Revista dos Tribunais, 2000.

VARELA, Marcelo Dias. Introdução ao direito à Reforma Agrária, o Direito Face aos Novos Conflitos Sociais.Leme: Editora de Direito, 1998.

ZAFFARONI, Eugenio Raúl. Em Busca das Penas Perdidas. Rio de Janeiro: Editora Revan, 2001. 